\title{
Properties of self-curing concrete containing bottom ash
}

Daud Mohamad ${ }^{1}$ *, Salmia Beddu ${ }^{1}$, Siti Nabihah Sadon ${ }^{1}$, Nur Liyana Mohd Kamal ${ }^{1}$, Zarina Itam ${ }^{1}$, Mohd Ariff Zainol ${ }^{1}$, Mohd Zakwan Ramli ${ }^{1}$, Wani Mohd Sapuan ${ }^{2}$

${ }^{1}$ Department of Civil Engineering, College of Engineering, University Tenaga Nasional, Selangor, Malaysia

${ }^{2}$ Civil Engineering Department, Infrastructure University, Kuala Lumpur, Malaysia

\section{A RT ICLE INFO}

\section{Article history:}

Received 19 March 2017

Received in revised form

3 September 2017

Accepted 8 September 2017

Keywords:

Self-curing

Bottom ash

Polyethylene glycol (PEG)

Compressive strength

Self-curing agent

\begin{abstract}
A B S T R A C T
In this study, the concrete consists of a mixture of self-curing agent, bottom ash, superplasticizer, water and cement. By adding self-curing agent in concrete, it can reduce water evaporation effect and therefore increase the water retention capacity of concrete compared with conventional concrete, which leads to, improved compressive strength. Bottom ash is the residue that is not capable of burning attached to the wall of the combustion process in the furnace. In previous studies, outcomes showed that the introduction of bottom ash to concrete could increase the level of hydration and compressive strength. The trend of self-curing concrete will be analyzed in detail. Furthermore, the lab scale testing will be conducted to determine the workability and mechanical properties by varying the percentage of selfcuring agent and bottom ash. The results reveal that Polyethylene Glycol (PEG) increase concrete workability and compressive strength compared to control mix. This promising result shows the potential of producing selfcuring concrete using bottom ash.
\end{abstract}

(C) 2017 The Authors. Published by IASE. This is an open access article under the CC BY-NC-ND license (http://creativecommons.org/licenses/by-nc-nd/4.0/).

\section{Introduction}

During the most recent decades, concrete technologies have been going through remarkable developments. Recently, self-curing concrete becomes popular due to its ability to provide extra moisture to the concrete without external curing (water or chemicals). Self-curing concept give advantages in mitigating limited curing sources due to labour negligence shortage of water in arid areas, the lack of access of structures in difficult terrains and in areas where the existence of fluorides in water will surely have an impact in the characteristics of concrete. The common ways of curing regularly fail in practice as reported by (Mousa et al., 2015a). Although curing process is meticulously performed, it can only reduce water evaporation but not with the water supply especially for the vertical structural elements. Avoid moisture content losses from the surface of flat concrete have been a challenging task for construction managers. If the evaporation of moisture from concrete are ignored it may result bad quality of that concrete such as plastic shrinkage cracks, poorly formed

\footnotetext{
* Corresponding Author.

Email Address: daud@uniten.edu.my (D. Mohamad) https://doi.org/10.21833/ijaas.2017.011.022

2313-626X/C) 2017 The Authors. Published by IASE.

This is an open access article under the CC BY-NC-ND license

(http://creativecommons.org/licenses/by-nc-nd/4.0/)
}

hydrated products, finishing problems and other surface defects. As according to Taylor (2013), curing is a chemical process that requires the presence of water over a certain period of time at suitable degrees to get the desired properties in the concrete mixture. It was reported by Bentz and Snyder (1999) that life-cycle cost reduction was found when internally cured high performance concrete (HPC) was used compared to normal concrete. PEG was found as a self-curing agent that improves concrete properties. Polyethylene Glycol (PEG) is a condensation polymer of ethylene oxide and water with the general formula $\mathrm{H}$ (OCH2CH2) $\mathrm{nOH}$, where is the average number of repeating oxyethylene groups typically from 4 to about 180 (Dhir et al., 1998).

PEG provides water retention throughout the concrete during curing process. Bottom ash was found to be one of the suitable materials to be used as fine aggregate to produce durable concrete (Singh and Siddique, 2013). Bottom ash is the companion to fly ash in process of coal-burning with an approximate amount of $20 \%$ by volume of the total ash agglomerated ash particles and formed in pulverized coal furnaces (Renforth et al., 2011). According to ACAA (2013) statistics on bottom ash for Utilization to Production Rate showed that $39.02 \%$ of all bottom ash produced is from Coal Combustion Product (CCP) Production. Coal Bottom 
Ash is uncombusted material that settles to the bottom of the boiler.

Therefore, this research is investigating the properties of self-curing concrete incorporating bottom ash as fine aggregate replacement. PEG is added to the concrete mix during mixing process and the concrete mix were left air cured in a room temperature after it has been molded.

\section{Methodology}

\subsection{Materials}

\section{Ordinary Portland cement}

Cement is produce from source of limestone, clay and iron ore. Mixing certain amount of limestone and clay or shale together any will through a heating process in a rotary kiln made OPC.

\section{Aggregates}

The purpose of aggregate in the concrete is generally caused by higher and has better durability. The coarse aggregates used have nominal maximum size of $20 \mathrm{~mm}$ referring in BS 812: Section 103.1: 1985. The coarse aggregate is cleaned, dried and prepared to be under surface saturated dry (SSD) condition.

\section{Water}

Water is the most important element in concrete, especially in holding the inert aggregate concrete when hard. Therefore, it is important to insist the use of water that is clean and free of mixed materials particularly undesirable chemical mixture. Mixing impurities in the water can greatly affect the strength and durability of concrete. Basically, the suitable $\mathrm{pH}$ water range for concrete mixing is around 6 to 8 .

\section{Superplasticizer}

Generally, superplasticizer is divided into many different types and brands. The type of superplasticizer used in this study is ViscoCrete $₫$ 2199. Sika ViscoCrete $\AA-2199$ is a high range water reducing admixture based on selected PCE polymers for promoting high ultimate and early strengths in both ready-mix and precast concrete. Sika ViscoCrete $囚-2199$ is chloride free according to BS 5075 and is compatible with all types of Portland cement including Sulphate Resistant Cement (SRC).

\section{Polyethylene glycol}

Polyethylene glycol is a polyether compound with many applications from industrial manufacturing to medicine. The structure of PEG is: $\mathrm{H}-1-\mathrm{OH}$ PEG is also known as polyethylene oxide or polyoxyethylene, depending on its molecular weight. The Polyethylene glycol has proved that it helps low the absorption of water in concrete. Generally, selfcuring agent used in this research is polyethylene glycol (Ch. Type). As is well known, the concept of polyethylene glycol (Ch. Type) is reduced water evaporation from concrete, and hence increases the water retention capacity of concrete compared with conventional concrete, which leads to improve the compressive strength. Results of this study demonstrate that a significant improvement took place in the physical properties studied for selfcuring concrete with polyethylene glycol (Ch.) as self-curing agent.

\section{Bottom ash}

Source of bottom ash in this study were taken from Jimah power plant, which located at Nilai, Negeri Sembilan. Generally, there are two different types of bottom ash; dry or wet bottom ash (boiler slag). Wet bottom ash tends to have more characteristics than regular dry bottom because of wet ash and bottom ash is solidified from the molten slag while dry bottom ash is the product of flaming straightforward process and Jimah Bottom ash were classified as dry bottom ash.

\section{Casting, curing and testing}

Casting, and testing procedure and method used is according to BS 1881. Firstly, sand will be mixed with half amount of water for approximately 3 minutes. Bottom ash and cement (OPC) were added and mixed for few minutes and the remaining water was added to the mix. After the mortar has well mixed, the mortar was casted in steel cubes $100 \mathrm{~mm}$ $x 100 \mathrm{~mm}$. After casting, the mortars were left in the casting room for 24 hours. Lastly, the sample were demoulded and placed in room temperature to required age of testing.

\section{Slump test}

The test is carried out using a mould known as a slump cone. The cone is placed on a hard nonabsorbent surface. Slump test is the process to determine the workability of concrete and will give the result of stiffness. The test is conduct using a slump cone. The cone is placed on a hard surface. This cone is filled with fresh concrete in four layers. Each layer is filled by $1 / 4$ of height of slump cone. It is tamped using a rod of standard dimensions for 25 times. This subsidence is termed as slump, and is measured in to the nearest $5 \mathrm{~mm}$ if the slump is $<100 \mathrm{~mm}$ and measured to the nearest $10 \mathrm{~mm}$ if the slump is $>100 \mathrm{~mm}$. Later in this paper, the result for slump test of $0 \%$ used polyethylene glycol control test concrete mix, $1 \%$ used polyethylene glycol concrete mix, $2 \%$ used polyethylene glycol concrete mix, 3\% used polyethylene glycol concrete mix and $4 \%$ used polyethylene glycol concrete mix will be shown.

\section{Compressive strength}

The test is carried out on $100 \times 100 \times 100 \mathrm{~mm}$ size cubes. The test specimens are marked and removed from the moulds and unless required for test within 24 hrs. A $2000 \mathrm{KN}$ capacity Compression Testing Machine (CTM) is used to conduct the test. The specimen is placed between the steel plates of the CTM and load is applied at the rate of 140 
$\mathrm{Kg} / \mathrm{Cm} 2 / \mathrm{min}$ and the failure load in $\mathrm{KN}$ is observed from the load indicator of the CTM. The result for compressive strength test in 7 days, 14 days, 21 days, 28 days followed by the percentage of polyethylene glycol will be shown in this paper.

\section{Material characterization}

\subsection{Chemical properties of the bottom ash}

In the investigation, an X-Ray microprobe system equipped at the Super Photon ring $8 \mathrm{GeV}$ (Spring-8), BL37XU can be used to identify the ultra-trace elements in the individual treated bottom ash (Whittaker et al., 2009). By applying this microanalytical technique based on the X-Ray fluorescence (XRF) method, multiple elements can be successfully analysed at femtogram level sensitivity. Their partial replacement in concrete replacing fine aggregate resulted in an increase in effective water/cement ratio as the small voids between the particles were filled and the compound become compacted.

\subsection{Microstructure}

The microstructure of bottom ash was observed using SEM (Scanning Electron Microscopy). From the images obtained, it can be seen that the bottom ash particles were porous and angular as shown in Fig. 1. Their partial replacement in concrete replacing fine aggregate resulted in an increase in effective water/cement ratio as the small voids between the particles were filled and the compound become compacted.

\subsection{Chemical composition of bottom ash}

Chemical analyses been conducted towards the bottom ash as to know the chemical or elements contained. X-ray fluorescence is an x-ray instrument which is used relatively non-destructive chemical analyses of fluids, sediments, minerals and rocks. The bottom ash collected to use in this experiment were not go through any treatment before.

It is very important to identify the elements contain in the bottom ash to study the reaction and how it influence the result and effect to the cubes (samples). Ferrous metal and non-ferrous metal also can be identified accurately by using x-ray fluorescence spectrometer. The results of from the XRF conducted on bottom ash in Table 1. From finding of chemical properties in Table 1, major Oxide content of Bottom Ash is Silica Oxide (SiO2) that contributes $48.5 \%$. SiO2 is a one of pozzolanic component that can increase the concrete strength. The appropriate air content can be reached by increasing the dosage of an air-entraining agent.

\subsection{Concrete mix design}

This research was carried out to determine the optimum percentage of Self-curing agent
(Polyethylene Glycol PEG 400) effect to the Bottom Ash concrete and carried out to determine workability and strength of self-curing concrete with the inclusion self-curing agent and bottom ash. The mix proportions to with percentage of $0,1,2,3 \& 4 \%$ of self-curing agent are tabulate in Table 2 and mix design were referring to British Design of Experiment (DOE) Method. The bottom ash samples were taken from Jimah Energy Ventures (JEV) Power Plant at Negeri Sembilan. The mix proportions of all samples are tabulated in Table 3. Concrete samples were design by cement (OPC), bottom ash, superplasticizer and self-curing agent (PEG).

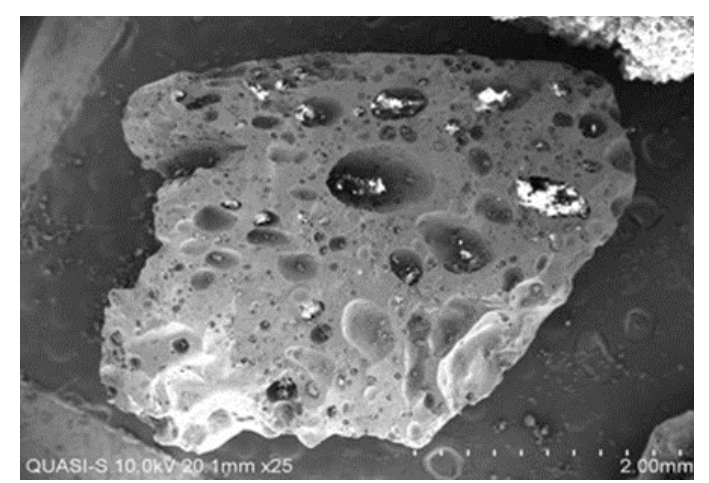

Fig. 1: SEM Image of bottom ash particles

Table 1: X-ray fluorescence data

\begin{tabular}{cccc}
\hline Formula & Concentration & Formula & Concentration \\
\hline $\mathrm{SiO} 2$ & $48.57 \%$ & $\mathrm{Si}$ & $22.70 \%$ \\
$\mathrm{Al} 203$ & $18.56 \%$ & $\mathrm{Al}$ & $9.82 \%$ \\
$\mathrm{Fe} 2 \mathrm{O} 3$ & $7.87 \%$ & $\mathrm{Fe}$ & $5.51 \%$ \\
$\mathrm{CaO}$ & $3.35 \%$ & $\mathrm{Mg}$ & $0.69 \%$ \\
$\mathrm{P} 2 \mathrm{O} 5$ & $1.16 \%$ & $\mathrm{P}$ & $0.51 \%$ \\
$\mathrm{TiO} 2$ & $1.15 \%$ & $\mathrm{Ba}$ & $0.14 \%$ \\
$\mathrm{MgO}$ & $1.15 \%$ & $\mathrm{~K}$ & $0.83 \%$ \\
$\mathrm{~K} 20$ & $1.00 \%$ & $\mathrm{Sr}$ & $0.09 \%$ \\
$\mathrm{SO} 3$ & $0.23 \%$ & $\mathrm{~W}$ & $0.09 \%$ \\
$\mathrm{BaO}$ & $0.16 \%$ & $\mathrm{Ti}$ & $0.69 \%$ \\
$\mathrm{SrO}$ & $0.11 \%$ & $\mathrm{Zr}$ & $0.04 \%$ \\
$\mathrm{WO} 3$ & $0.11 \%$ & $\mathrm{Ni}$ & $0.03 \%$ \\
$\mathrm{ZrO} 2$ & $0.05 \%$ & $\mathrm{Co}$ & $0.02 \%$ \\
$\mathrm{MnO}$ & $0.04 \%$ & $\mathrm{Cu}$ & $65 \mathrm{PPM}$ \\
$\mathrm{NiO}$ & $0.03 \%$ & $\mathrm{Ca}$ & $2.39 \%$ \\
$\mathrm{CoO}$ & $0.03 \%$ & $\mathrm{Y}$ & $63 \mathrm{PPM}$ \\
$\mathrm{CuO}$ & $82 \mathrm{PPM}$ & $\mathrm{S}$ & $0.09 \%$ \\
$\mathrm{Y} 203$ & $80 \mathrm{PPM}$ & $\mathrm{Rb}$ & $42 \mathrm{PPM}$ \\
$\mathrm{Rb} 20$ & $46 \mathrm{PPM}$ & $\mathrm{Mn}$ & $0.03 \%$ \\
$\mathrm{Nb} 205$ & $22 \mathrm{PPM}$ & $\mathrm{Nb}$ & $16 \mathrm{PPM}$ \\
\hline
\end{tabular}

\section{Experimental result}

\subsection{Properties of fresh concrete}

\section{Workability}

Extensive data were collect from testing to ensure the sample achieve the objective to produce a selfcuring cubes by using polyethylene glycol and Bottom Ash and to investigate the compressive strength of self-curing cubes by comparing with the compressive strength of control mix. The slump test result presented in Fig. 2 and Table 3 show that as the percentage of used PEG is increased the slump value will also increase. When comparing the slump value of $0 \%$ used PEG and 4\% used PEG, it shows an increasing of slump value from $65 \mathrm{~mm}$ to $75 \mathrm{~mm}$. It 
can be stated that, the workability of self-curing

concrete increase with the inclusion of PEG.

Table 2: Concrete mix proportion

\begin{tabular}{cccccccc}
\hline Mix no. & Target Grade of concrete $(\mathrm{MPa})$ & Cement $\left(\mathrm{kg} / \mathrm{m}^{3}\right)$ & Water $(\mathrm{kg} / \mathrm{m} 3)$ & $\mathrm{SP}(\%)$ & $\mathrm{PEG}(\%)$ & $\mathrm{CA}\left(\mathrm{kg} / \mathrm{m}^{3}\right)$ & $\mathrm{BA}\left(\mathrm{kg} / \mathrm{m}^{3}\right)$ \\
\hline CM & 40 & 400 & 120 & 8 & - & 1252 \\
2 & 40 & 400 & 120 & 8 & 1 & 1252 \\
3 & 40 & 400 & 120 & 8 & 2 & 1252 \\
4 & 40 & 400 & 120 & 8 & 3 & 1252 \\
5 & 40 & 400 & 120 & 4 & 4 & 674 \\
\hline
\end{tabular}

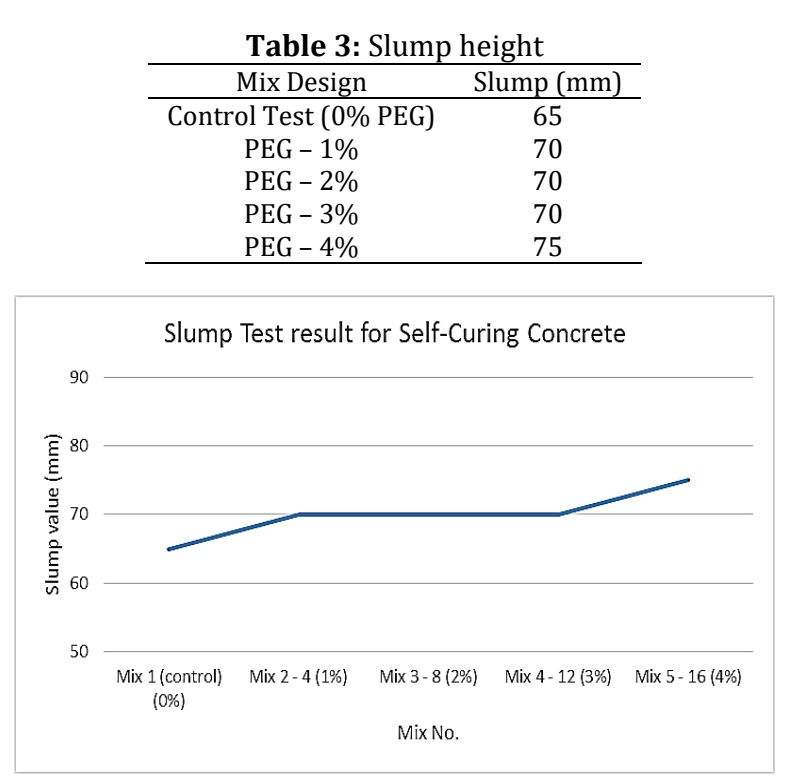

Fig. 2: Slump test result

The slump test result in Fig. 2 shows that as the percentage of used polyethylene glycol is increased the slump value will also increase. When comparing the slump value of control mix $(0 \%)$ used polyethylene glycol and $4 \%$ used polyethylene glycol, it shows an increasing of slump value from 65 $\mathrm{mm}$ to $75 \mathrm{~mm}$. Therefore, this proved that the addition of used polyethylene glycol in the concrete can act as water reducer's agent and at the same time has the ability to increase the workability of the concrete.

\subsection{Properties of hardened concrete}

\section{Compressive strength}

The test is carried out on $100 \times 100 \times 100 \mathrm{~mm}$ size cubes and it was performed according to ASTM C109. Each samples tested three times with three different cubes. The test specimens are marked and removed from the moulds and unless required for test within $24 \mathrm{hrs}$. A $2000 \mathrm{KN}$ capacity Compression Testing Machine (CTM) is used to conduct the test. The specimen is placed between the steel plates of the CTM and load is applied at the rate of 140 $\mathrm{Kg} / \mathrm{Cm} 2 / \mathrm{min}$ and the failure load in $\mathrm{KN}$ is observed from the load indicator of the CTM. Table 4 and Fig. 3 show the strength development of all mixes. From the result obtained, all samples show the increment with ages. Overall, self-curing concrete show higher compressive strength compared to control mix. It can be revealed that PEG contributes to the strength development. Water retention provided by PEG increase effectiveness hydration of cement and reduced self-desiccation and it supported by (Mousa et al., 2015b).

Table 4: Compressive strength

\begin{tabular}{ccccc}
\hline \multirow{2}{*}{ Mix No } & \multicolumn{4}{c}{ Compressive Strength, MPa } \\
\cline { 2 - 5 } & 7 day & 14 day & 21 day & 28 day \\
\hline 1 & 17.01 & 10.52 & 21.50 & 18.17 \\
2 & 14.1 & 14.20 & 14.36 & 24.23 \\
3 & 16.13 & 21.50 & 24.35 & 31.92 \\
4 & 10.56 & 18.17 & 25.89 & 31.47 \\
5 & 23.60 & 25.86 & 35.11 & 38.82 \\
\hline
\end{tabular}

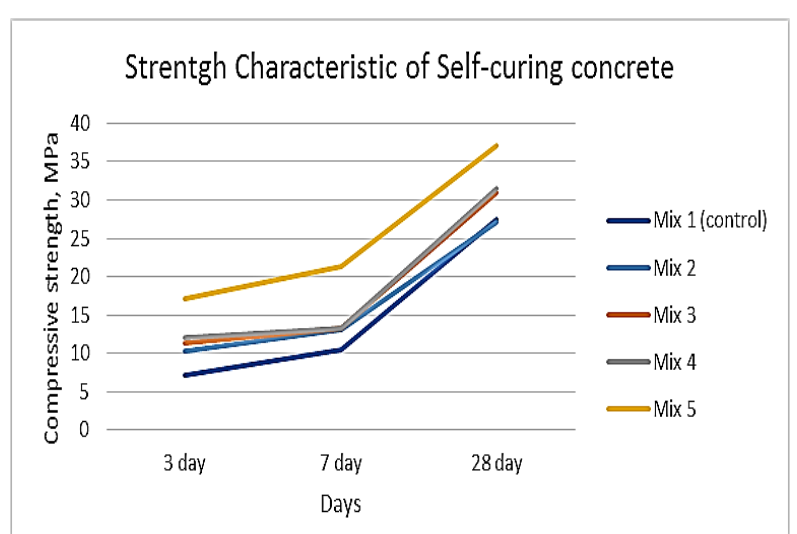

Fig. 3: Strength Development of Self-curing concrete

The compressive strength of all the concretes studied either self-curing or conventional concretes (reference concrete), which increase gradually with time in different rates under air curing. At 21 days concrete with $2 \%, 3 \%$ and $4 \%$ PEG give higher compressive strength. It is well known that, the concept of polyethylene-glycol (ch. type) is to reduce water evaporation from concrete, and hence increase the water retention capacity of concrete compared with conventional concrete, which leads to improved compressive strength.

\section{Conclusion}

As conclusion, the consequences of self-curing concrete using waste materials as Bottom Ash in the mixture as fine aggregate during this research give a potential result to be implemented as a fine aggregate. The results were obviously showed that the objective of this project has been achieved. It can eventually be concluded as the following:

- The first objective of the project is to determine the effect of self-curing concrete containing Bottom Ash as a replacement to fine aggregate to workability, PEG give impart significant different in improve concrete workability.

-The second objective of the project is to determine the effect of self-curing concrete containing Bottom 
Ash as a replacement to fine aggregate to compressive strength, PEG improve compressive strength of concrete containing Bottom Ash compared to control mix with different percentage of PEG.

\section{Acknowledgment}

This work was supported in part by UNITEN Internal Grant.

\section{References}

ACAA (2013). Coal combustion products (CCP) Production and use survey report. American Coal Ash Association, Michigan, USA.

Bentz DP and Snyder KA (1999). Protected paste volume in concrete: Extension to internal curing using saturated lightweight fine aggregate. Cement and Concrete Research, 29(11): 1863-1867.
Dhir RK, Hewlett PC, and Dyer TD (1998). Mechanisms of water retention in cement pastes containing a self-curing agent. Magazine of Concrete Research, 50(1): 85-90.

Mousa MI, Mahdy MG, Abdel-Reheem AH, and Yehia AZ (2015a). Mechanical properties of self-curing concrete (SCUC). HBRC Journal, 11(3): 311-320.

Mousa MI, Mahdy MG, Abdel-Reheem AH, and Yehia AZ (2015b). Physical properties of self-curing concrete (SCUC). HBRC Journal, 11(2): 167-175.

Renforth P, Washbourne CL, Taylder J, and Manning DAC (2011). Silicate production and availability for mineral carbonation. Environmental Science and Technology, 45(6): 2035-2041.

Singh M and Siddique R (2013). Effect of coal bottom ash as partial replacement of sand on properties of concrete. Resources, Conservation and Recycling, 72: 20-32.

Taylor PC (2013). Curing concrete. CRC Press, Boca Raton, USA.

Whittaker M, Taylor R, Li S, Li Q, and Black L (2009). The behaviour of finely ground bottom ash in Portland cement. In the 29th Cement and Concrete Science Conference, Leeds, UK: 70-73. Available online at: http://eprints.whiterose.ac.uk/ 9778/2/Whittaker.pdf 